\title{
Autonomy, respect for autonomy and weakness of will
}

\author{
Raanan Gillon Imperial College Health Service and St Mary's Hospital Medical School, London University
}

In this issue of the journal Christopher McKnight challenges the usefulness of the concept of autonomy and of the principle of respect for autonomy in the cases of patients who are what philosophers call (in this context synonymously) weak-willed, incontinent or akratic (1). Since it is reasonable to regard us all as at least intermittently weak-willed his arguments, if valid, would be of considerable importance. In assessing them it is important to be clear about the Davidsonian definition of weakness of will which $\mathrm{Mr}$ McKnight adopts, whereby an agent acts 'incontinently' (or akratically or with weakness of will) if and only if he or she, knowing that all things considered, to do y would be better than to do $x$, and knowing that he or she is capable of doing $y$, nonetheless intentionally does $\mathrm{x}$. Thus if, all things considered, I think it would be better not to eat pate de foie gras and yet I deliberately and hedonistically eat it then I am manifesting incontinence, weakness of will, or akrasia.

$\mathrm{Mr}$ McKnight writes that such weak-willed actions 'do not fit well into a taxonomy such as is often adopted in writings on medical ethics which divides patients into the autonomous and the nonautonomous. As a result ... the principle of respect for autonomy fails to yield a determinate answer as to how a patient should be treated'. The problem, he argues, is that the possibility of weak-willed action forces us to distinguish between a rational agent who sometimes acts irrationally and a non-rational agent who is incapable either of rational or of irrational action. 'Declaring an akratic agent autonomous classifies him together with an ordinary non-akratic agent; declaring him non-autonomous involves putting him in with non-rational beings such as animals, comatose patients and those in advanced stages of Alzheimer's Disease. Neither classification is comfortable'. He then gives two examples, one of which, the case of $\mathrm{Mr}$ Jones who refuses a life-saving blood transfusion because of his irrational fear of needles, is intended to show a case of such weakwilled action, and to show the unhelpfulness and lack of illumination afforded by the principle of respect for autonomy.

The steps in his argument seem to be: first the (implicit) claim that it is irrational to act in any way other than that which one considers the best way to act in the circumstances, all things considered - ie $\vec{\bullet}$ that it is irrational to act akratically. Second, given that it is irrational, people who act thus cannot be $\vec{\bullet}$ rational. Third, to be autonomous one must be $\mathrm{G}$ rational. Therefore, fourth, people who act from weakness of will cannot properly be regarded as $\vec{\nabla}$ autonomous. Fifth, the principle of respect for autonomy cannot apply to persons who cannot $\mathbb{Q}$ properly be regarded as autonomous. Sixth, if $\bar{\square}$ patients manifest weakness of will, as in the case of $\stackrel{\mathbb{D}}{\frac{1}{2}}$ $\mathrm{Mr}$ Jones, the principle of respect for autonomy can- $\vec{\theta}$ not properly be applied to them and thus canne $\Theta$ help doctors to decide how to respond to such cases

There are various available counterargumento but the main problem with such a line of argument is, surely, that many would simply reject its first premise, counter-arguing that it can be rational to act in a way that one acknowledges to be other than the best way. In this counterargument, 'rational' simply means 'on the basis of reasoning' (one of its ordinary meanings), and thus actions based on reasoning can properly be called rational even if the reasoning is imperfect, morally or otherwise, and even if the actions are not intended to be the best actions in the circumstances all things considered.

If this view is accepted Mr McKnight's argument, as reconstructed above, loses its crucial first premise and fails. A person can be rational in this sense, despite acting in a way that he or she recognises is not for the best all things considered. Such a weak- $\frac{T}{O}$ willed action can still be autonomous, the person can still be properly acknowledged as an autonomous $\mathcal{N}$ (albeit weak-willed) agent, and thus the person $N$ should, prima facie, have his or her autonomy $\mathrm{C}$ respected.

Moreover, it is instructive to consider the implications of accepting Mr McKnight's first premise and ensuing argument. Because there can be very few - if any - people in real life who always act for the best all things considered, by $\mathrm{Mr}$ McKnight's argument 0 all the rest of us should be regarded as weak-willed $\mathbb{D}$ and therefore irrational (in his sense) and therefore $\frac{\Omega}{\mathbb{D}}$ non-autonomous. Thus, if $\mathrm{Mr}$ McKnight's argu- $\frac{\varrho}{0}$ ment is successful the principle of respect for autonomy becomes irrelevant not only for difficult cases 
of the sort he considers but also in the cases of all, or almost all, ordinary people.

The key to unlocking this apparent conundrum is surely to recall that the principle of respect for autonomy applies to all (and only) those who have adequate autonomy. Its scope is not restricted to those (mythical) super-rational persons who are 'fully autonomous' (another mythical concept) and/or who always act for the best, all things considered. At the same time restriction of its scope to those with adequate autonomy excludes, in certain circumstances, those who, though autonomous in the sense of being able to make decisions for themselves based on reason, are not adequately autonomous for their autonomy to require respect where such respect would be against their interests as perceived by appropriate others. Young children and the severely mentally immature, ill, disabled or impaired are unlikely to be adequately autonomous in this sense.

According to this approach, while optimal rationality is not necessary for autonomy, rationality, in the sense of capacity for reasoning, properly remains a necessary condition: necessary but not sufficient. This is a most important aspect of Mr McKnight's paper, for it reminds us that a variety of attributes other than reasoning capacity are needed for a person to be sufficiently or adequately autonomous for that autonomy to require respect even when others think that such respect is against the person's best interests, even where the person agrees that this is so, and even when the person agrees that such respect would not be for the best all things considered.

What other attributes, in addition to reasoning capacity, might be necessary for a person to have 'adequate autonomy'? There are several plausible additional candidates (2). One is an adequate knowledge-base for that reasoning (including adequate capacity to perceive the world accurately without, for example, gross distortion by hallucinations or delusions). A further candidate is adequate experience of the world, not only to have sufficient knowledge for adequate reasoning but also to be able to use that knowledge and reasoning for adequate predictions about the outcomes of alternative courses of action, including their likely effects on oneself and others. (Maybe it is the lack of this experiential component that accounts for our tendency to ascribe inadequate autonomy to children even when their reasoning ability is adequate). Another plausible candidate is, as $\mathrm{Mr} \mathrm{McKnight}$ indicates, adequate will power - an adequate ability to will and/or to intend to do that which our reason leads us towards. Without adequate will power a person cannot be autonomous and this is manifest recurrently in psychiatric contexts, notably in severe depression and in obsessive compulsive disorders.

To return to Mr McKnight's case, on this analysis, before we can decide how to treat Mr Jones, who refuses a life-saving transfusion because he does not want a needle in his vein, we must assess whether his autonomy is sufficiently severely impaired for him properly to be regarded as inadequately autonomous for his decisions to be respected when they will lead to his death or severe harm. If he is adequately autonomous we should prima facie respect his decision; if not we should prima facie override it paternalistically in order to save his life.

Unfortunately we do not have enough information to decide - we have a 'thin' rather than a 'thick' account of the patient and his situation. If on further inquiry it became clear that he was suffering from a severe mental disorder (and certainly there is prima facie reason to suspect that someone who does not wish to die but adamantly rejects life-saving treatment because he is afraid of needles, and for no other reason, is severely mentally disordered) then we should be justified in regarding him as inadequately autonomous to have his life-threatening decisions respected. If on the other hand further questioning elicits that he has no severe mental illness, that as well as being afraid of needles he also has a stable commitment to being a Jehovah's Witness or a Christian Scientist, and thus to a way of life that eschews blood products or medical intervention respectively, regardless of risk to life and health, then we should be justified in regarding him as adequately autonomous to refuse life-saving medical interventions and to have such refusal respected, however painful and wasteful of human life we may find such respect to be.

Of course there are a host of remaining problems, especially practical problems, associated with this approach. Given, however, that they are not insuperable, it allows us to continue to assess patients on the basis of the criterion of adequate autonomy; is the patient adequately autonomous for his or her autonomy prima facie to require respect even where such respect militates against what we consider to be the patient's best interests? It also remains a useful criterion for the more general moral requirement of respecting each other's autonomy even in cases where we believe it would be in another's best interests to override his or her autonomy. It is moreover a criterion that is entirely consistent with our acknowledgement that we are all less than fully autonomous, all less than fully informed, all less than fully wise, clever and determined, and that we all manifest, at least intermittently, akrasia, incontinence or weakness of will. Our acknowledgement, that is, that we are all human.

\section{Reference}

(1) McKnight C. Autonomy and the akratic patient. Fournal of medical ethics 1993; 19: 206-210.

(2) Impaired autonomy and rejection of treatment [editorial]. Fournal of medical ethics 1983; 9: 131-132. 